\title{
A Cyclooxygenase 2 Gene Polymorphism is a Risk Factor for the Complication of Medication Overuse Headaches in Patients with Migraines
}

\author{
Masakazu Ishii ${ }^{1 *}$, Hirotaka Katoh ${ }^{2}$, Tatsuya Kurihara ${ }^{1}$, Ken-ichi Saguchi ${ }^{3}$, Yoshiyuki Miyasaka ${ }^{4}$, Shunichi Shimizu ${ }^{1,5}$ and Mitsuru Kawamura $^{2}$ \\ ${ }^{1}$ Department of Pharmacology, Toxicology and Therapeutics, Division of Physiology and Pathology, Showa University School of Pharmacy, Tokyo 142-8555, Japan \\ ${ }^{2}$ Department of Neurology, Showa University School of Medicine, Tokyo 142-8666, Japan \\ ${ }^{3}$ Department of Pharmacy Education, Showa University School of Pharmacy, Tokyo 142-8555, Japan \\ ${ }^{4}$ Department of Hospital Pharmaceutics, Showa University School of Pharmacy, Tokyo 142-8555, Japan \\ ${ }^{5}$ Laboratory of Pharmacology, Department of Clinical Pharmacy, Yokohama College of Pharmacy, Yokohama 245-0066, Japan
}

"Corresponding author: Masakazu Ishii, Department of Pharmacology, Toxicology and Therapeutics, Division of Physiology and Pathology, Showa University School of Pharmacy, Tokyo 142-8555, Japan, Tel: 81-3-3784-8041; Fax: 81-3-3786-0481; E-mail: masakazu@pharm.showa-u.ac.jp

Rec date: Dec 03, 2014, Acc date: Jan 30, 2015, Pub date: Feb 01, 2015

Copyright: @ 2015 Ishii M, et al. This is an open-access article distributed under the terms of the Creative Commons Attribution License, which permits unrestricted use, distribution, and reproduction in any medium, provided the original author and source are credited.

\begin{abstract}
We determined whether cyclooxygenase-2 (COX-2) gene polymorphisms were involved in the aggravation of migraines due to the overuse of medication. Polymorphisms in the COX-2 (rs20417, rs689466) gene were examined. Forty-seven patients with migraine (6 males and 41 females; 5 with migraines with aura (MA), 36 with migraines without aura (MO), 6 with MA + MO; 1 with MA and 21 with MO; $36.4 \pm 10.3$ years) and 22 patients with medication overuse headache $(\mathrm{MOH})(1$ male and 21 females; $39.6 \pm 9.9$ years $)$ who had migraines participated in this study. The genotypes of each polymorphism were analyzed by polymerase chain reaction (PCR)-restriction fragment length polymorphism (RFLP) methods. No significant differences were observed in the genotypic distributions of $\mathrm{rs} 20417(\mathrm{C} / \mathrm{C}+\mathrm{G} / \mathrm{C}$ vs. $\mathrm{G} / \mathrm{G}, \mathrm{p}=0.220$ ) between migraine patients and $\mathrm{MOH}$ patients. The frequencies of the rs689466 G/G genotype were significantly higher in patients with $\mathrm{MOH}$ than in patients with migraines ( $G / G$ vs. $A / A+A / G, p=0.008$ ). Furthermore, the frequencies of the rs689466 $G / G$ genotype were significantly higher in patients with $\mathrm{MOH}$ who had migraines without aura $(M O)$ than in patients with $M O(G / G$ vs. $A / A+A / G, p=0.001$ ). The results of this study showed that the COX-2 polymorphism (rs689466) was independently related with the complication of $\mathrm{MOH}$ in patients with $\mathrm{MO}$.
\end{abstract}

\section{Key words:}

Medication Overuse Headache; Migraine; Polymorphism; Cyclooxygenase-2

\section{Introduction}

Migraine patients are susceptible to developing medication overuse headaches $(\mathrm{MOH})$ due to the overuse of medication [1-3]. Moreover, $56.8 \%$ of migraine sufferers use over-the-counter medicine (combination analgesics) alone [4], and $85.1 \%$ of $\mathrm{MOH}$ patients overuse combination analgesics [2]. Although most patients return to the episodic migraine pattern after drug withdrawal, the complications of $\mathrm{MOH}$ markedly decrease the quality of life of patients [1]. Furthermore, in contrast to migraine patients, the percentage of comorbidity with depression in $\mathrm{MOH}$ patients is higher [3-5]. Therefore, it is important to prevent the complications of $\mathrm{MOH}$ in patients with migraines.

Nonsteroidal anti-inflammatory drugs (NSAIDs) and acetaminophen have been used to treat headaches in patients with migraines. NSAIDs inhibit cyclooxygenase (COX) and reduce the production of prostanoids such as prostaglandin $\mathrm{I}_{2}$. However, the overuse of these drugs can cause $\mathrm{MOH}$ [6-8]. Martelletti et al. showed that COX-2 was up-regulated in migraine patients [9]. Dasdemir et al. also reported that a COX-2 polymorphism (rs689466) was a risk factor for migraines without aura (MO) [10]. Additionally, $\mathrm{MOH}$ patients who have migraines as the primary headache initially had MO [1].
Therefore, rs689466 may contribute to the pathogenesis of not only $\mathrm{MO}$, but also $\mathrm{MOH}$. However, to the best of our knowledge, there have been no studies on the relationship between COX-2 gene polymorphisms and $\mathrm{MOH}$.

Therefore, we conducted the present study to investigate the relationship between COX-2 gene polymorphisms and $\mathrm{MOH}$.

\section{Methods}

\section{Subjects}

We enrolled 47 migraine patients (6 males and 41 females; 5 with migraines with aura (MA), 36 with migraines without aura (MO), 6 with MA + MO; $36.4 \pm 10.3$ years) and $22 \mathrm{MOH}$ patients (1 male and 21 females; 1 with MA and 21 with MO; $39.6 \pm 9.9$ years) who were admitted to the Department of Neurology in the outpatient clinic of Showa University East Hospital, Tokyo, Japan, between May, 2010 and January, 2011. These patients had participated in a previous study, in which the incidence of depression was shown to be significantly higher in $\mathrm{MOH}$ patients than in migraine patients $(\mathrm{p}<0.001)$ [11]. The duration of migraine history was not significantly different between migraine patients $(16.5 \pm 13.0$ years, $\mathrm{n}=44)$ and $\mathrm{MOH}$ patients $(20.39$ $\pm 12.7, \mathrm{n}=19, \mathrm{p}=0.276$ ). The overused medications were combination analgesics in 14 patients (64\%), analgesics in 9 patients $(41 \%)$, and triptans in 2 patients (9\%) [11]. Migraines were diagnosed according to the International Classification of Headache Disorders, 2nd Edition 
Page 2 of 3

(ICHD-II) in 2004 [12]. We also confirmed with an interview that the migraine patients in the present study had not previously overused medication. The revised ICHD-II criteria were used for the diagnosis of $\mathrm{MOH}[1]$. Headache specialists asked $\mathrm{MOH}$ patients about primary headaches, and confirmed primary headaches after the recovery of patients from $\mathrm{MOH}$, according to the ICHD-II criteria. Although the subjects included in the present study were not only patients with migraines, but also patients with migraines and tension-type headaches, patients with tension-type headaches only were excluded from this study. We used the Diagnostic and Statistical Manual of Mental Disorders, Fourth Edition (DSM-IV) to diagnose major depressive disorder [13].

All patients were Japanese. We enrolled all patients with migraines and patients with $\mathrm{MOH}$ who provided informed consent for this study, and did not select patients. The Ethics Committee for Genome Research of Showa University approved this clinical study.

\section{Genotyping}

The determination of COX-2 gene polymorphisms (rs20417 and rs689466) was performed by a polymerase chain reaction (PCR)-based method in accordance with Dasdemir et al. [10]. The sense oligonucleotide primer for rs20417 was 5'-AGG CAG GAA ACT TTA TAT TGG- - 3 ', and the antisense primer was 5'-ATG TTT TAG TGA CGA CGC TTA-3'. PCR products were digested for $10-12 \mathrm{~h}$ at $37^{\circ} \mathrm{C}$ with Aci I. The $309 \mathrm{bp}$ fragment indicated the presence of the $\mathrm{C}$ allele (no Aci I restriction site) and the $209 \mathrm{bp}$ and $100 \mathrm{bp}$ fragments indicated the presence of the $G$ allele (presence of Aci I restriction site). The sense oligonucleotide primer for rs689466 was 5'-CCC TGA GCA CTA CCC ATG AT-3', and the antisense primer was 5'-GCC TTC ATA GGA GAT ACT GG-3'. PCR products were digested for $10-12 \mathrm{~h}$ at $37^{\circ} \mathrm{C}$ with Pvu II. The $273 \mathrm{bp}$ fragment indicated the presence of the A allele (no Pvu II restriction site) and the $220 \mathrm{bp}$ and $53 \mathrm{bp}$ fragments indicated the presence of the $\mathrm{G}$ allele (presence of the Pvu II restriction site).

The PCR products or restriction enzyme-treated PCR fragments were run on $3 \%$ agarose gels and stained with ethidium bromide.

\section{Statistical analysis}

We applied univariate analysis using unpaired Student's t test for continuous variables, and $\chi^{2}$ test or Fisher's exact test for categorical variables. Statistical significance was accepted at the $p<0.05$ level. The analysis was performed using Excel Statistics (Excel Toukei) 2008 for Windows (Social Survey Research Information Co., Tokyo, Japan).

\section{Results}

No significant differences were observed in the genotypic distributions of $\mathrm{rs} 20417(\mathrm{C} / \mathrm{C}+\mathrm{G} / \mathrm{C}$ vs $\mathrm{G} / \mathrm{G}, \mathrm{p}=0.220)$ between migraine patients and $\mathrm{MOH}$ patients (Table 1). The frequencies of the rs689466 G/G genotype were significantly higher in patients with $\mathrm{MOH}$ than in patients with migraines ( $\mathrm{G} / \mathrm{G}$ vs. $\mathrm{A} / \mathrm{A}+\mathrm{A} / \mathrm{G}, \mathrm{p}=0.008$; Table 1). As shown in Table 2, the frequencies of the rs689466 G/G genotype were significantly higher in patients with $\mathrm{MOH}$ who had $\mathrm{MO}$ than in patients with $\mathrm{MO}(\mathrm{G} / \mathrm{G}$ vs. $\mathrm{A} / \mathrm{A}+\mathrm{A} / \mathrm{G}, \mathrm{p}=0.001)$.

\begin{tabular}{|c|c|c|c|c|c|c|c|c|}
\hline & & Subje & & Migra & & МOH & & \\
\hline & & $n=69$ & (\%) & $n=47$ & (\%) & $\mathrm{n}=\mathbf{2 2}$ & $(\%)$ & $P$ \\
\hline rs20417 & $\mathrm{C} / \mathrm{C}$ & 1 & 1.4 & 0 & 0.0 & 1 & 4.5 & \\
\hline & $\mathrm{G} / \mathrm{C}$ & 12 & 17.4 & 7 & 14.9 & 5 & 22.7 & \\
\hline & $\mathrm{G} / \mathrm{G}$ & 56 & 81.2 & 40 & 85.1 & 16 & 72.7 & \\
\hline & $\begin{array}{l}\mathrm{C} / \mathrm{C}, \\
\mathrm{G} / \mathrm{C}\end{array}$ & 13 & 18.8 & 7 & 14.9 & 6 & 27.3 & 0.220 \\
\hline & $\mathrm{G} / \mathrm{G}$ & 56 & 81.2 & 40 & 85.1 & 16 & 72.7 & \\
\hline rs689466 & $\mathrm{A} / \mathrm{A}$ & 21 & 30.4 & 13 & 27.7 & 8 & 36.4 & \\
\hline & $\mathrm{A} / \mathrm{G}$ & 34 & 49.3 & 29 & 61.7 & 5 & 22.7 & \\
\hline & G/G & 14 & 20.3 & 5 & 10.6 & 9 & 40.9 & \\
\hline & $\begin{array}{l}\mathrm{A} / \mathrm{A}, \\
\mathrm{A} / \mathrm{G}\end{array}$ & 55 & 79.7 & 42 & 89.4 & 13 & 59.1 & $0.008^{*}$ \\
\hline & $\mathrm{G} / \mathrm{G}$ & 14 & 20.3 & 5 & 10.6 & 9 & 40.9 & \\
\hline
\end{tabular}

Table 1: Distribution of Genotype Frequencies for COX-2 Polymorphisms.

\begin{tabular}{|c|c|c|c|c|c|c|c|c|}
\hline & & Subje & & MO & & $\mathrm{MOH}$ & & \\
\hline & & $\mathrm{n}=57$ & (\%) & $n=36$ & (\%) & $\mathrm{n}=\mathbf{2 1}$ & (\%) & \\
\hline rs689466 & $\mathrm{A} / \mathrm{A}$ & 18 & 31.6 & 10 & 27.8 & 8 & 38.1 & \\
\hline & $\mathrm{A} / \mathrm{G}$ & 28 & 49.1 & 24 & 66.7 & 4 & 19 & \\
\hline & $\mathrm{G} / \mathrm{G}$ & 11 & 19.3 & 2 & 5.6 & 9 & 42.9 & \\
\hline & $\begin{array}{l}\mathrm{A} / \mathrm{A}, \\
\mathrm{A} / \mathrm{G}\end{array}$ & 46 & 80.7 & 34 & 94.4 & 12 & 57.1 & $0.001^{*}$ \\
\hline & $\mathrm{G} / \mathrm{G}$ & 11 & 19.3 & 2 & 5.6 & 9 & 42.9 & \\
\hline
\end{tabular}

Table 2: Distribution of Genotype Frequencies for COX-2 Polymorphism between MO patients and MOH patients who had MO.

\section{Discussion}

The present study was the first to demonstrate that the COX-2 rs689466 polymorphism contributed to the complications of $\mathrm{MOH}$ in patients with migraines, especially $\mathrm{MO}$, and $\mathrm{G} / \mathrm{G}$ genotype carriers appeared to be more susceptible to the aggravation of migraines by the overuse of medications.

A high percentage of $\mathrm{MOH}$ patients initially have $\mathrm{MO}$ [1]. In this study, although the difference was not significant, we found that $\mathrm{MOH}$ patients who had $\mathrm{MO}$ as primary headaches were slightly more common than MO patients in the migraine group. Furthermore, the frequency of comorbidity with depression was higher in $\mathrm{MOH}$ patients than in migraine patients [3-5]. We also confirmed that the prevalence of depression was significantly higher in $\mathrm{MOH}$ patients than in 
Citation: Ishii M, Katoh H, Kurihara T, Saguchi K, Miyasaka Y, et al. (2015) A Cyclooxygenase 2 Gene Polymorphism is a Risk Factor for the Complication of Medication Overuse Headaches in Patients with Migraines. J Neurol Disord 3: 206. doi:10.4172/2329-6895.1000206

Page 3 of 3

migraine patients. Among the 22 patients with $\mathrm{MOH}, 64 \%$ overused combination analgesics, a finding that is similar to those of Imai et al. [2] and Kanki et al. [3]. Although the sample size in this study was small, the background of subjects appears to be coincident with those found in previous studies.

The COX-2 rs689466 polymorphism is located in a core c-MYB recognition sequence in the COX-2 promoter region, and the DNA/cMYB complex binds to the rs689466 A allele, but not to the rs689466 G allele [14]. Furthermore, a previous study showed significantly lower transcriptional activity and mRNA levels in the rs689466 G allele than in the rs689466 A allele, both in vitro and in vivo [14]. Therefore, the expression of this enzyme may have been lower in individuals carrying the rs689466 $\mathrm{G}$ allele in the $\mathrm{MOH}$ group.

The G/G genotype in rs689466 has been related to the pathogenesis of MO [10], but not depression [15]. The results of the present study suggest that the $\mathrm{G} / \mathrm{G}$ genotype in rs689466 is a risk factor for $\mathrm{MOH}$ in patients with migraine. Moreover, this is a risk factor for the complication of $\mathrm{MOH}$ in patients with $\mathrm{MO}$. Although migraine patients may be complicated by $\mathrm{MOH}$ in the future, a significant difference was observed in COX-2 rs689466 between the MO and $\mathrm{MOH}$ groups in this study. Therefore, we showed that rs689466 may be one of the risk factors contributing to the aggravation of MO due to the overuse of medications. Since the sample size is the biggest limitation of the study, future studies with a larger sample must be undertaken to elucidate the relationship between rs689466 and $\mathrm{MOH}$ in more detail.

\section{Acknowledgements}

We thank Mirei Yahara, a student at the Showa University School of Pharmacy, for her technical assistance. This study was supported in part by a grant from the Private University High Technology Research Center Project, and a matching fund subsidy from the Ministry of Education, Culture, Sport, Science, and Technology, Japan (MEXT).

\section{References}

1. Headache Classification Committee, Olesen J, Bousser MG, Diener HC, Dodick D, et al. (2006) New appendix criteria open for a broader concept of chronic migraine. Cephalalgia 26: 742-746.
2. Imai N, Kitamura E, Konishi T, Suzuki Y, Serizawa M, et al. (2007) Clinical features of probable medication-overuse headache: a retrospective study in Japan. Cephalalgia 27: 1020-1023.

3. Kanki R, Nagaseki Y, Sakai F (2008) Medication-overuse headache in Japan. Cephalalgia 28: 1227-1228.

4. Sakai F, Igarashi H (1997) Prevalence of migraine in Japan: a nationwide survey. Cephalalgia 17: 15-22.

5. Kaji Y, Hirata K (2009) Characteristics of mood disorders in Japanese patients with medication-overuse headache. Intern Med 48: 981-986.

6. Meskunas CA, Tepper SJ, Rapoport AM, Sheftell FD, Bigal ME (2006) Medications associated with probable medication overuse headache reported in a tertiary care headache center over a 15-year period. Headache 46: 766-772.

7. Coppola G, Currà A, Di Lorenzo C, Parisi V, Gorini M, et al. (2010) Abnormal cortical responses to somatosensory stimulation in medication-overuse headache. BMC Neurol 10: 126.

8. Starling AJ, Hoffman-Snyder C, Halker RB, Wellik KE, Vargas BB, et al. (2011) Risk of development of medication overuse headache with nonsteroidal anti-inflammatory drug therapy for migraine: a critically appraised topic. Neurologist 17: 297-299.

9. Martelletti P, Zicari A, Realacci M, Fiore G, De Filippis S, et al. (2001) Expression of NOS-2, COX-2 and Th1/Th2 cytokines in migraine. J Headache Pain 2: S51-S56.

10. Dasdemir S, Cetinkaya Y, Gencer M, Ozkok E, Aydin M, et al. (2013) Cox-2 gene variants in migraine. Gene 518: 292-295.

11. Onaya T, Ishii M, Katoh H, Shimizu S, Kasai H, et al. (2013) Predictive index for the onset of medication overuse headache in migraine patients. Neurol Sci 34: 85-92.

12. Headache Classification Subcommittee of the International Headache Society (2004) The International Classification of Headache Disorders: (2ndedn.) Cephalalgia 24 Suppl 1: 9-160.

13. Pitcher TM, Piek JP, Barrett NC (2002) Timing and force control in boys with attention deficit hyperactivity disorder: subtype differences and the effect of comorbid developmental coordination disorder. Hum Mov Sci 21: 919-945.

14. Zhang X, Miao X, Tan W, Ning B, Liu Z, et al. (2005) Identification of functional genetic variants in cyclooxygenase- 2 and their association with risk of esophageal cancer. Gastroenterology 129: 565-576.

15. Su KP, Huang SY, Peng CY, Lai HC, Huang CL, et al. (2010) Phospholipase A2 and cyclooxygenase 2 genes influence the risk of interferon-alpha-induced depression by regulating polyunsaturated fatty acids levels. Biol Psychiatry 67: 550-557. 